\title{
A Two-Step Approach for Diagnosing Glutamate Dehydrogenase Genes by Conventional Polymerase Chain Reaction from Clostridium difficile Isolates
}

\author{
Sepideh Khodaparast ${ }^{1}$, Ashraf Mohabati Mobarez ${ }^{1, *}$, Mehdi Saberifiroozi $^{2}$
}

1. Department of Bacteriology, Faculty of Medical Sciences, Tarbiat Modares University. Tehran, Iran.

2. Digestive Disease Research Institute, Tehran University of Medical Sciences, Tehran, Iran.

3.

\section{* Corresponding Author:}

Ashraf Mohabati Mobarez Department of Bacteriology, Faculty of Medical Sciences, Tarbiat Modares University, P.O.Box: 14115-111, Tehran, Iran

Tel: +982182883862

Fax: + 982182884555

Email:mmmobarez@modares.ac.ir

Received: 09 Jan. 2019

Accepted: 10 May 2019

\section{ABSTRACT}

\section{BACKGROUND}

Clostridium difficile is the major causative agent of nosocomial antibiotic-associated colitis. The gold standard for $C$. difficile detection is stool culture followed by cytotoxic assay, although it is laborious and time-consuming. We developed a screening test based on a two-step conventional polymerase chain reaction (PCR) approach to detect $g l u \mathrm{D}$, the glutamate dehydrogenase (GDH) enzyme gene, which is a marker for screening of $C$. difficile. Targeting gluD comparing to the conserved stable genetic element of pathogenicity locus (PaLoc), with an accessory gene of $C d d 3$, was an effective method for the detection of this pathogen from patients with enterocolitis.

\section{METHODS}

Fresh fecal samples of the patients who were clinically suspicious for antibiotic-associated colitis were collected. Stool specimens were cultured on the cycloserine-cefoxitin fructose agar (CCFA) in an anaerobic condition, following alcohol shock treatment and enrichment in Clostridium difficile Brucella broth (CDBB). On confirmed colonies, PCR was carried out for detection of PaLoc subsidiary gene, $C d d 3$, and toxicogenic genes, $t c d \mathrm{~A}$ and $t c d \mathrm{~B}$. The $g l u \mathrm{D}$ that is GDH gene detection was performed by conventional PCR on the extracted DNA from 578 fresh stool samples.

\section{RESULTS}

$57(9.8 \%)$ strains of $C$. difficile were approved by conventional PCR for $g l u D$ and $C d d 3$ genes, in which $37(6.4 \%)$ colonies had $t c d \mathrm{~A}+/ t c d \mathrm{~B}+$ genotype, $2(0.3 \%) t c d A+/ t c d B-, 4(0.7 \%) t c d \mathrm{~A}-/$ $t c d \mathrm{~B}+$ and the remaining $14(2.4 \%)$ colonies were $t c d \mathrm{~A}$ and $t c d \mathrm{~B}$ negative.

\section{CONCLUSION}

These results demonstrate that targeting $g l u \mathrm{D}$ by PCR is quite promising for rapid detection of C. difficile from fresh fecal samples. Furthermore, the multiple-gene analysis for $t c d \mathrm{~A}$ and $t c d \mathrm{~B}$ assay proved a reliable approach for diagnosing of toxigenic strains among clinical samples.

\section{KEYWORDS:}

Clostridium difficile, Colitis, Toxigenic culture, $C d d 3, \operatorname{gl} l u \mathrm{D}, t c d \mathrm{~A}, t c d \mathrm{~B}$

Please cite this paper as:

Khodaparast S, Mohabati Mobarez A, Saberifiroozi M. A Two-Step Approach for Diagnosing Glutamate Dehydrogenase Genes by Conventional Polymerase Chain Reaction from Clostridium difficile Isolates. Middle East J Dig Dis 2019;11:135-140. doi:10.15171/mejdd.2019.139.

\section{INTRODUCTION}

Clostridium difficile (C. difficile) is an anaerobic spore-forming gram-positive bacillus, which is the major cause of widespread diseases such as self-limiting diarrhea or fatal colitis upon antibiotic treatments. The main toxicogenic causes of $C$. difficile infections are two large Clostridia toxins; an enterotoxin $(T c d \mathrm{~A})$ and a cytotoxin $(T c d \mathrm{~B})$. As well as inflammation and fluid secretion, Clostridial exotoxins bind to the human intestinal cells and are responsible 
for the damage to the intestinal mucosa. Various types of virulence factors contribute to the pathogenicity of C. difficile within the gastrointestinal tract. The most significant change in cells treated with $T c d \mathrm{~A}$ or $T c d \mathrm{~B}$ is the loss of cytoskeletal structure. $T c d \mathrm{~B}$ binds and enters the colonic epithelium, which causes a series of inflammatory reactions as a cytotoxin; otherwise, $T c d \mathrm{~A}$ is an enterotoxin. $^{1,2}$ The symptoms of the related infection depend on toxin-encoding pathogenicity locus (PaLoc) in the bacterial genome. The PaLoc is a conserved and stable genetic unit, which is $19.6 \mathrm{~kb}$ and contains the $t c d \mathrm{~A}$ and $t c d \mathrm{~B}$ genes. Other PaLoc genes are $t c d \mathrm{R}$ and $t c d \mathrm{C}$, which encode positive and negative regulators for $t c d \mathrm{~A}$ and $t c d \mathrm{~B}$ toxins. The PaLoc is located at the same site on the chromosome and includes three additional tcd open reading frames (ORFs), $t c d \mathrm{D}, t c d \mathrm{E}$, and $t c d \mathrm{C}$, and ORFs for the insertion sequences $c d d-2, c d d-3$ that located upstream and downstream of the PaLoc, present in both non-toxigenic and toxigenic strains. ${ }^{3-5}$

Studies on $C$. difficile indicated that it has the ability to ferment low molecular weight substrates of amino acids. Glutamate has the main dependence of the other amino acid metabolism. Glutamate dehydrogenase (GDH) is a constructor enzyme produced in large amounts by all strains of $C$. difficile independent of their toxigenic or non-toxigenic forms. ${ }^{6,7}$ Detection of this enzyme by immunoassay methods has been considered a valid technique with proper sensitivity for the screening of C. difficile in stool samples. ${ }^{8}$ More comprehensive diagnostic assays for $C$. difficile infection are based on clinical symptoms in combination with laboratory tests for screening $C$. difficile toxins and GDH. ${ }^{9}$ GDH enzyme detection methods do not distinguish between toxigenic and non-toxigenic strains, thus a toxin assay is required while a definitive diagnosis is necessary. In addition, approaching toxin is essential for epidemiological research, optimal management, and prevention programs. ${ }^{10}$ Molecular methods for the diagnosis of $C$. difficile infection have been studied far less than those used to diagnose other infectious diseases. Various nucleic acid amplification tests are commonly used for detection of toxigenic $C$. difficile. ${ }^{11}$ The known high sensitivity ( $93 \%$ to $100 \%$ ) of nucleic acid amplification assays is useful in the confirmation of GDH gene or other toxin assays, but it should be noted that it is only useful in the acute disease and to verify false positive cases. ${ }^{12,13}$ The European Society of Clinical Microbiology and Infectious Diseases recommended a two-step algorithm detecting GDH as a screening method combined with toxigenic culture or cytotoxic assays. ${ }^{14}$

We developed a two-step approach by toxigenic culture and conventional PCR assay for comparing the outbreak of GDH gene ( $g l u \mathrm{D})$ to the PaLoc accessory gene of $C d d 3$. For an additional confirmation survey, we also detected toxin-positive samples by conventional PCR test for $t c d \mathrm{~A} \& t c d \mathrm{~B}$ genes.

\section{MATERIALS AND METHODS}

\section{Patients' samples:}

A total of 578 fresh diarrheal stool specimens of patients with enterocolitis were collected from hospital inpatients with a history of prolonged antibiotic therapy (1 to 8 weeks) in the period from 2015 to 2018 .

\section{Toxigenic culture:}

The stool samples were transported at room temperature and cultured within 8 hours after collection, or stored at $4^{\circ} \mathrm{C}$, for no more than 48 hours before being cultured. Toxigenic culture based on the anaerobic culture of stool samples from 2-5 days was used as a reference procedure for $C$. difficile diagnosis. Since the bacteria are spore-forming, all the stool samples were treated with the alcoholic shock. The samples were divided to two equal parts, one exposed to $96 \%$ ethanol for 1 hour and the other was enriched in Clostridium difficile Brucella broth (CDBB) for 1 minute supporting the vegetative forms of C. difficile. ${ }^{15}$ The treated samples were subsequently plated on selective agar, cycloserine-cefoxitin fructose agar (CCFA), and incubated in an anaerobic chamber (Gas Pack Anaerocult ${ }^{\circledR}$ A Merk) at $37^{\circ} \mathrm{C}$ for at least 2-5 days. After isolation in CCFA medium, the presence of C. difficile was confirmed by gram stain, colony morphology, and detection of "horse-barn" odor. ${ }^{16}$

\section{Molecular methods:}

DNA extraction:

Each isolated strain from cultures was transferred with an inoculating loop into a $1.5 \mathrm{~mL}$ microcentrifuge tube containing $200 \mathrm{~mL}$ of sterile PBS buffer, and bacterial DNA was extracted using the QIAamp kit (Qiagen, Germany), according to the manufacturer's instructions. 
Table 1: Primers sequence used for amplification of $C d d 3, \operatorname{gluD}, t c d \mathrm{~B}$, and $t c d \mathrm{~A}$ genes

\begin{tabular}{|c|c|c|c|c|}
\hline Gene & Primer & Sequence: 5 ----> 3 ' & Product size (bp) & Ref. \\
\hline$t c d \mathrm{~A}$ & $\begin{array}{l}\text { TA1 } \\
\text { TA2 }\end{array}$ & $\begin{array}{l}\text { 5'-ATG ATA AGG CAA CTT CAG TGG-3' } \\
\text { 5'-TAA GTT CCT CCT GCT CCA TCA A-3' }\end{array}$ & $624 \mathrm{bp}$ & 17 \\
\hline$t c d \mathrm{~B}$ & $\begin{array}{l}\text { TB1 } \\
\text { TB2 }\end{array}$ & $\begin{array}{c}\text { 5'-GAG CTG CTT CAA TTG GAG AGA-3' } \\
\text { 5'-GTA ACC TAC TTT CAT AAC ACC AG-3' }\end{array}$ & $412 \mathrm{bp}$ & 17 \\
\hline$C d d 3$ & $\begin{array}{l}\text { Tim6 } \\
\text { Struppi6 }\end{array}$ & $\begin{array}{l}\text { 5'-TCC AAT ATA ATA AAT TAG CAT TCC A -3' } \\
\text { 5'-GGC TAT TAC ACG TAA TCC AGA TA -3' }\end{array}$ & $622 \mathrm{bp}$ & 17 \\
\hline GDH & $\begin{array}{l}g l u \mathrm{D} 1 \\
g l u \mathrm{D} 2\end{array}$ & $\begin{array}{l}\text { 5 '-TGTCAGGAAAAGATGTAAATGTCTTCGAG-3' } \\
\text { 5'-TTAGTACCATCCTCTTAATTTCATAGCTTC-3’ }\end{array}$ & 1278 bp & 18 \\
\hline
\end{tabular}

Table 2: Comparison of the conventional PCR results with the toxigenic culture of Clostridium difficile

\begin{tabular}{lcccc}
\hline C. difficile strains & tedA & tcdB & gluD & Cdd3 \\
\hline $37(6.4 \%)$ & + & + & + & + \\
\hline $2(0.3 \%)$ & + & - & + & + \\
\hline $4(0.7 \%)$ & - & + & + & + \\
\hline $14(2.4 \%)$ & - & - & + & + \\
\hline 0 & - & - & - & - \\
\hline Total & 39 & 41 & 57 & 57 \\
$57(9.8 \%)$ & $(6.7 \%)$ & $(7.1 \%)$ & $(9.8 \%)$ & $(9.8 \%)$ \\
\hline
\end{tabular}

\section{Nucleic acid amplification:}

Detection of $C d d 3$, glutamate dehydrogenase ( $g l u \mathrm{D})$, toxin $\mathrm{A}(t c d \mathrm{~A})$, and toxin $\mathrm{B}(t c d \mathrm{~B})$ genes was performed by multiplex conventional PCR test, in which melting temperature for both primer sets was over $600 \mathrm{C}$ so that the annealing and the extension steps could be combined into a single step. The specific primer sequences are presented in table 1 . The PCR reactions were carried out using $2 \times$ Mix RED Master Mix (Amplicon, Denmark), $40 \mathrm{pmol}$ of the respective primer pair for each reaction, and $5 \mu \mathrm{L}$ of the extracted DNA. The PCR procedure was included a denaturing step for $1 \mathrm{~min}$ at $95^{\circ} \mathrm{C}$ and annealing at $52^{\circ} \mathrm{C}$ for $1 \mathrm{~min}$, followed by a $1 \mathrm{~min}$ extension at $72^{\circ} \mathrm{C}$ for 40 cycles. A final extension step was done at $72^{\circ} \mathrm{C}$ for $10 \mathrm{~min}$.

\section{Detection of amplified products:}

Amplified products were visualized by running $5 \mu \mathrm{L}$ of the reaction mixture on a $1 \%$ agarose gel immersed in Tris-acetate-EDTA(TAE) at $100 \mathrm{~V}$ for $60 \mathrm{~min}$. Gels were stained by adding DNA Safe Stain (SinaClon BioScience Co.) and visualized under UV light.

\section{RESULTS}

\section{Study population}

This study was performed on 578 samples obtained from Shariati and Milad General Hospitals, Tehran, Iran. The appearances of stool samples were unformed, loose, bloody, or watery. All of the patients had a history of antibiotic therapy from 1-8 weeks, most of them treated with beta-lactam, quinolone, and some with vancomycin and metronidazole.

\section{Routine toxigenic culture:}

A total of $62(10.7 \%)$ stool specimens grew in toxigenic culture. DNA of $C$. difficile colonies was extracted using the Qiagen DNA extraction kit. The PCR results for the $g l u \mathrm{D}$ gene in $57(9.8 \%)$ strains of the cultured samples were positive. Moreover, all of the colonies were also positive by PCR on the $C d d 3$ gene. Detection of $t c d \mathrm{~A}$ $\& t c d \mathrm{~B}$ genes were subsequently carried out by conventional PCR assay from the extracted DNA of isolated $C$. difficile from toxigenic culture.

Toxigenic strains were retrieved in 57 colonies $(9.8 \%$ frequency), $t c d \mathrm{~A} 39$ (6.7\%), and $t c d \mathrm{~B} 41$ (7.1\%), in which $37(6.4 \%)$ colonies had the $t c d \mathrm{~A}+/ t c d \mathrm{~B}+$ genotype, $2(0.3 \%)$ had $t c d \mathrm{~A}+/ t c d \mathrm{~B}-, 4(0.7 \%)$ had $t c d \mathrm{~A}-/$ $t c d \mathrm{~B}^{+}$, and the remaining $14(2.4 \%)$ colonies had $t c d \mathrm{~A}$ and $t c d \mathrm{~B}$ negative genotype (table 2, figure 1).

\section{DISCUSSION}

We used a two-step method to detect $C$. difficile from stool specimens including toxigenic cultures followed by conventional PCR method. The toxigenic culture was performed after fecal samples treatment with the alcoholic shock, which was twice and also selective enrichment medium (CDBB) that was three times more effec- 


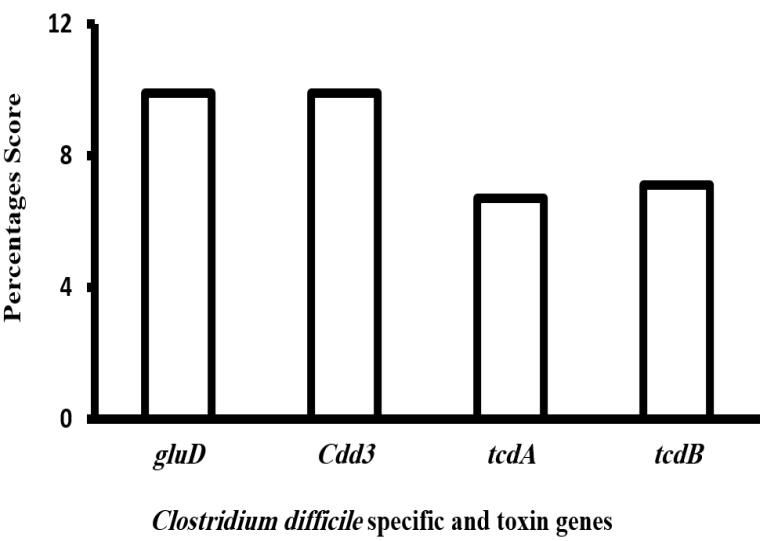

Fig.1: Column chart of the frequency of the $g l u \mathrm{D}, C d d 3, t c d \mathrm{~A}$, and $t c d \mathrm{~B}$

tive than direct plating for detection of $C$. difficile disable in forming spores. The main finding of our study is the high number of the clinical samples tested for detection of Clostridium difficile by toxigenic culture. Also comparing the GDH based PCR assay with the specific gene of $C d d 3$ does not differentiate between toxigenic and non-toxigenic $C$. difficile species. ${ }^{19-21}$

C. difficile has been identified as the causative organism of antibiotic-associated colitis in humans. ${ }^{22}$ Prevention and management of Clostridium difficile infection are challenging issues. The optimized laboratory diagnosis of $C$. difficile infection remains controversial. ${ }^{23}$ Many laboratories designed algorithms for screening the presence of a $C$. difficile common antigen, $\mathrm{GDH}$, as a marker for the presence of the organism in the stool. ${ }^{24}$ The increase in the outbreak of Clostridium difficile infection in different populations has been proportional to the rate of hypervirulent species. The presence of GDH is not specific to toxin-producing $C$. difficile types. ${ }^{25}$ However, molecular assays detecting GDH or $C$. difficile toxin genes $(t c d \mathrm{~A}$ and $t c d \mathrm{~B})$ represent high sensitivity for differentiating the toxin-producing strains. ${ }^{26,27}$

Our study showed $9.8 \%$ frequency of antibioticassociated colitis and demonstrated that PCR of $t c d \mathrm{~A}$ and $t c d \mathrm{~B}$ toxin genes could be used as a rapid method for confirmation of the toxigenic potential of $C$. difficile isolates. The toxin gene profile results have shown that among 57 strains of $C$. difficile isolated from patients' stools, $14(2.4 \%)$ strains were non-toxigenic A-B-, 37 $(6.4 \%)$ strains were toxigenic $\mathrm{A}+\mathrm{B}+, 2(0.3 \%)$ strains were toxin $\mathrm{A}+\mathrm{B}-$, and the remaining $4(0.7 \%)$ strains were $\mathrm{A}-\mathrm{B}+$. The reports of our survey for the frequency of $9.8 \%$ highlight the consistent outbreak of $C$. difficile infection rated from $6 \%$ to $21 \%$ in several countries such as Europeans and American ones. ${ }^{28-31}$ There are several reports about the prevalence of $C$. difficile in Iran. Rates differ from $6 \%$ in Crohn's disease to $15.3-20 \%$ in hospitalized $C$. difficile infection detected by alternative methods such as PCR or Loop mediated isothermal amplification (LAMP) and also molecular typing. ${ }^{32-35}$ There are fewer reports of antibiotic-associated Clostridium difficile infection (CDI) outbreaks in our country. That is why we suggest a local epidemic occurrence should be confirmed by further epidemiological methods such as pulse-field electrophoresis or ribotyping.

Removal of PCR inhibitors from fecal samples through the PCR reaction is critical which is why the direct use of molecular methods of the samples are limited. C. difficile infections are not commonly diagnosed and reported in Iran. Moreover, in the studied intensive care units where documented cases have been admitted, infection rates are not clear. It may be due to inadequate knowledge on the part of the clinicians concerning the clinical detection of the infection. Another reason may be related to the use of a low sensitivity toxin assays employed in the diagnostic laboratories instead of the toxigenic culture and cytotoxic assays, which has caused further problems and is time-consuming.

\section{CONCLUSION}

Availability of proper laboratory methods has a significant influence on documentation of CDI frequency. The use of a procedure for microbiological analysis, which can implement a unique method improves the monitoring of CDI incidence and helps in understanding its epidemiological prevalence. Furthermore, it is important that clinicians be instructed to adopt and apply the most reliable diagnostic strategies, which targeting nucleic acids, including endpoint or real-time PCR methods for detection of the genes like those encoding GDH and $T c d \mathrm{~A}$ and/or $T c d \mathrm{~B}$ toxins.

\section{ACKNOWLEDGMENT}

We would like to thank all the staff working in the microbiology labs of Shariati Hospital for their cooperation in collecting samples. We also thank professor Vasei for his helpful comments in manuscript preparation. 
This study was supported by a grant from Digestive Disease Research Institute (grant No: 96-04-37-36742).

\section{ETHICAL APPROVAL}

There is nothing to be declared.

\section{CONFLICT OF INTEREST}

The authors declare no conflict of interest related to this work.

\section{REFERENCES}

1. Orrell KE, Zhang Z, Sugiman-Marangos SN, Melnyk RA. Clostridium difficile toxins A and B: Receptors, pores, and translocation into cells. Crit Rev Biochem Mol Biol 2017;52:461-73. doi:10.1080/10409238.2017.1325831.

2. Chandrasekaran R, Lacy DB. The role of toxins in Clostridium difficile infection. FEMS Microbiol Rev 2017;41:723-50. doi:10.1093/femsre/fux048.

3. Martin-Verstraete I, Peltier J, Dupuy B. The Regulatory Networks That Control Clostridium difficile Toxin Synthesis. Toxins (Basel) 2016;8. doi:10.3390/toxins8050153.

4. Aktories K, Schwan C, Jank T. Clostridium difficile Toxin Biology. Annu Rev Microbiol 2017;71:281-307. doi: 10.1146/annurev-micro-090816-093458.

5. Brouwer MS, Mullany P, Allan E, Roberts AP. Investigating Transfer of Large Chromosomal Regions Containing the Pathogenicity Locus Between Clostridium difficile Strains. Methods Mol Biol 2016;1476:215-22. doi: 10.1007/978-1-4939-6361-4_16.

6. Girinathan BP, Braun S, Sirigireddy AR, Lopez JE, Govind R. Importance of Glutamate Dehydrogenase (GDH) in Clostridium difficile Colonization In Vivo. PloS One 2016;11:e0160107. doi:10.1371/journal.pone.0160107.

7. Girinathan BP, Braun SE, Govind R. Clostridium difficile glutamate dehydrogenase is a secreted enzyme that confers resistance to H2O2. Microbiology 2014;160:47-55. doi:10.1099/mic.0.071365-0.

8. Yoldas O, Altindis M, Cufali D, Asik G, Kesli R. A Diagnostic Algorithm for the Detection of Clostridium difficile-Associated Diarrhea. Balkan Med J 2016;33:80-6. doi:10.5152/balkanmedj.2015.15159.

9. Moon HW, Kim HN, Hur M, Shim HS, Kim H, Yun YM. Comparison of Diagnostic Algorithms for Detecting Toxigenic Clostridium difficile in Routine Practice at a Tertiary Referral Hospital in Korea. PloS One 2016;11:e0161139. doi:10.1371/journal.pone.0161139.

10. Sokol H, Lalande V, Landman C, Bourrier A, Nion-Larmurier I, Rajca S, et al. Clostridium difficile infection in acute flares of inflammatory bowel disease: A prospective study. Dig Liver Dis 2017;49:643-6. doi:10.1016/j.dld.2017.01.162.

11. Martinez-Melendez A, Camacho-Ortiz A, Morfin-Otero R, Maldonado-Garza HJ, Villarreal-Trevino L, Garza-
Gonzalez E. Current knowledge on the laboratory diagnosis of Clostridium difficile infection. World J Gastroenterol 2017;23:1552-67. doi:10.3748/wjg.v23.i9.1552.

12. Fairley DJ, McKenna JP, Stevenson M, Weaver J, Gilliland C, Watt A, et al. Association of Clostridium difficile ribotype 078 with detectable toxin in human stool specimens. $\mathrm{J} \mathrm{Med}$ Microbiol 2015;64:1341-5. doi:10.1099/jmm.0.000165.

13. Morales L, Rodriguez C, Gamboa-Coronado MDM. Molecular detection of Clostridium difficile on inert surfaces from a Costa Rican hospital during and after an outbreak. Am J Infect Control 2016;44:1517-9. doi:10.1016/j. ajic.2016.09.003.

14. Crobach MJ, Planche T, Eckert C, Barbut F, Terveer EM, Dekkers OM, et al. European Society of Clinical Microbiology and Infectious Diseases: update of the diagnostic guidance document for Clostridium difficile infection. Clin Microbiol Infect 2016;22 Suppl 4:S63-81. doi: 10.1016/j.cmi.2016.03.010.

15. Cadnum JL, Hurless KN, Deshpande A, Nerandzic MM, Kundrapu S, Donskey CJ. A Sensitive and Selective Culture Medium for Detection of Environmental Clostridium difficile without the Requirement for Anaerobic Culture Conditions. J Clin Microbiol 2014;52:3259-63. doi: 10.1128/JCM.00793-14.

16. Legaria MC, Rollet R, Di Martino A, Castello L, Barberis $\mathrm{C}$, Rossetti MA, et al. Detection of toxigenic Clostridium difficile: usefulness of two commercially available enzyme immunoassays and a PCR assay on stool samples and stool isolates. Rev Argent Microbiol 2018;50:36-44. doi:10.1016/j.ram.2017.01.002.

17. Cohen SH, Tang YJ, Silva J Jr. Analysis of the pathogenicity locus in Clostridium difficile strains. J Infect Dis 2000;181:659-63. doi:10.1086/315248.

18. Origuen J, Corbella L, Orellana MA, Fernandez-Ruiz M, Lopez-Medrano F, San Juan R, et al. Comparison of the clinical course of Clostridium difficile infection in glutamate dehydrogenase-positive toxin-negative patients diagnosed by PCR to those with a positive toxin test. Clin Microbiol Infect 2018;24:414-21. doi:10.1016/j. cmi.2017.07.033.

19. Terveer EM, Crobach MJ, Sanders IM, Vos MC, Verduin CM, Kuijper EJ. Detection of Clostridium difficile in Feces of Asymptomatic Patients Admitted to the Hospital. J Clin Microbiol 2017;55:403-11. doi:10.1128/JCM.01858-16.

20. Ramos Martinez A, Ortiz Balbuena J, Asensio Vegas A, Sanchez Romero I, Munez Rubio E, Cantero Caballero $\mathrm{M}$, et al. Characteristics of Clostridium difficile infection in patients with discordant diagnostic test results. Rev Esp Enferm Dig 2016;108:304-8. doi:10.17235/ reed.2016.4052/2015.

21. Shin BM, Lee EJ, Moon JW, Lee SY. Evaluation of the VIDAS glutamate dehydrogenase assay for the detection of Clostridium difficile. Anaerobe 2016;40:68-72. doi: 10.1016/j.anaerobe.2016.06.001.

22. Rineh A, Kelso MJ, Vatansever F, Tegos GP, Hamblin MR. Clostridium difficile infection: molecular pathogen- 
esis and novel therapeutics. Expert Rev Anti Infect Ther 2014;12:131-50. doi:10.1586/14787210.2014.866515.

23. Ong GK, Reidy TJ, Huk MD, Lane FR. Clostridium difficile colitis: A clinical review. Am J Surg 2017;213:56571. doi:10.1016/j.amjsurg.2016.10.035.

24. Kachrimanidou M, Tegou Z, Chasampalioti M, Arvaniti K, Protonotariou E, Skoura L. A two-step approach improves the diagnosis of Clostridium difficile infection. J Microbiol Methods 2017;143:17-9. doi:10.1016/j.mimet.2017.09.015.

25. Mawer DPC, Eyre DW, Griffiths D, Fawley WN, Martin JSH, Quan TP, et al. Contribution to Clostridium Difficile Transmission of Symptomatic Patients With Toxigenic Strains Who Are Fecal Toxin Negative. Clin Infect Dis 2017;64:1163-70. doi:10.1093/cid/cix079.

26. Manthey CF, Dranova D, Christner M, Berneking L, Kluge S, Lohse AW, et al. Stool cultures at the ICU: get rid of it!. Ann Intensive Care 2018;8:10. doi:10.1186/ s13613-018-0358-x.

27. Munoz M, Rios-Chaparro DI, Herrera G, Soto-De Leon SC, Birchenall C, Pinilla D, et al. New Insights into Clostridium difficile (CD) Infection in Latin America: Novel Description of Toxigenic Profiles of Diarrhea-Associated to CD in Bogota. Colombia. Front Microbiol 2018;9:74. doi:10.3389/fmicb.2018.00074.

28. Bauer MP, Notermans DW, van Benthem BH, Brazier JS, Wilcox MH, Rupnik M, et al. Clostridium difficile infection in Europe: a hospital-based survey. Lancet 2011;377:63-73. doi:10.1016/S0140-6736(10)61266-4.

29. Cheknis AK, Sambol SP, Davidson DM, Nagaro KJ, Mancini MC, Hidalgo-Arroyo GA, et al. Distribution of Clostridium difficile strains from a North American, European and Australian trial of treatment for C. difficile infections: 2005-2007. Anaerobe 2009;15:230-3. doi: 10.1016/j.anaerobe.2009.09.001.

30. Stallmach A, Reuken PA, Teich N. [Advances in the diagnosis and treatment of Clostridioides [Clostridium] difficile infections in inflammatory bowel disease]. Zeitschrift fur Gastroenterologie 2018;56:1369-77.

31. Rezazadeh Zarandi E, Mansouri S, Nakhaee N, Sarafzadeh F, Iranmanesh Z, Moradi M. Frequency of antibiotic associated diarrhea caused by Clostridium difficile among hospitalized patients in intensive care unit, Kerman, Iran. Gastroenterol Hepatol Bed Bench 2017;10:229-34.

32. Sadeghifard N, Salari MH, Ghassemi MR, Eshraghi S, Amin Harati F. The incidence of nosocomial toxigenic clostridium difficile associated diarrhea in Tehran tertiary medical centers. Acta Med Iran 2010;48:320-5.

33. Jalali M, Khorvash F, Warriner K, Weese JS. Clostridium difficile infection in an Iranian hospital. BMC Res Notes 2012;5:159. doi:10.1186/1756-0500-5-159.

34. Goudarzi M, Goudarzi H, Alebouyeh M, Azimi Rad M, Shayegan Mehr FS, Zali MR, et al. Antimicrobial susceptibility of clostridium difficile clinical isolates in iran. Iran Red Crescent Med J 2013;15:704-11. doi:10.5812/ircmj.5189.
35. Azimirad M, Krutova M, Nyc O, Hasani Z, Afrisham $\mathrm{L}$, Alebouyeh M, et al. Molecular typing of Clostridium difficile isolates cultured from patient stool samples and gastroenterological medical devices in a single Iranian hospital. Anaerobe 2017;47:125-8. doi:10.1016/j.anaerobe.2017.05.004. 